\title{
Applying the Wikihouse Constructive System in Architecture Atelier: from teaching to the materialization of urban furniture
}

\author{
Carla Cristina Secchi \\ Universidade Comunitária da Região de Chapecó - UNOCHAPECÓ | Brasil | \\ cah_secchi@unochapeco.edu.br \\ Luana Peroza Piaia \\ Universidade Comunitária da Região de Chapecó - UNOCHAPECÓ | Brasil | \\ luanapiaia@unochapeco.edu.br

\section{Paola Avila} \\ Universidade Comunitária da Região de Chapecó - UNOCHAPECÓ | Brasil | \\ paola.avila@unochapeco.edu.br
}

\author{
Ana Luisa Scariot \\ Universidade Comunitária da Região de Chapecó - UNOCHAPECÓ | Brasil | \\ anascariot@unochapeco.edu.br
}

\begin{abstract}
The Wikihouse model combines parameterization with production of housing in the short term. By inserting these methodologies in the graduation course, the students are approached to innovative and efficient solutions. This research reports the applying of the WikiHouse version 3.0 in architecture classroom, having as final product an urban furniture. It is constructed from the experience in a Higher Education Institution, from theory to manufacturing. Positive and negative points are pointed out, as well the response of the final product. The proposal contributes to the perception of new forms of production by students, from digital fabrication and prototyping.
\end{abstract}

Keywords: WikiHouse; Design Process; Urban Furniture; Teaching; Digital Fabrication.

\section{INTRODUÇÃO}

As tecnologias de fabricação digital têm sido popularizadas e facilitadas pela gradativa expansão dos Fab Labs (fabrication laboratories). Estes espaços dispõem de maquinários controlados por computador (Passaro \& Rohde, 2015) e permitem novas formas de fabricação, construção e avaliação na arquitetura (Pupo, 2009). Desde 1991, com a chegada da internet, o acesso a arquivos compartilhados em rede aumenta gradativamente (Passaro \& Rohde, 2015), sustentando o surgimento do conceito open source na arquitetura (Parvin, 2013). A Open Source Architecture (OSArc), ou Arquitetura de Fonte Aberta, alterou a forma de criação, produção e fabricação na construção, tendo como princípios a abordagem colaborativa e participativa online (Ratti, 2011). Percebe-se novo arranjo, em que a rede interliga o arquiteto, o cliente e a fábrica, isto é, não há mais necessidade de estarem próximos fisicamente (Secchi, 2019).

Neste sentido, pode-se citar como um dos precursores desta prática, o modelo habitacional WikiHouse, desenvolvido pelo escritório de design e arquitetura Studio 00, de Alastair Parvin e Nick lerodiaconou, em 2011 (Parvin, 2013). Este sistema construtivo é viabilizado pelo uso de softwares paramétricos, que possibilitam a interação entre diferentes elementos produzidos, atribuindo valores e expressões, que assim controlam suas ações (Mendonça, Passaro, \& Henriques, 2018). Por meio deste conjunto de tecnologias e conceitos, amplia-se a ideia de projetar, inovar e produzir habitações a curto prazo, possibilitando a criação de formatos originais ou alterações em existentes, interferindo também no ensino.

De acordo com Lawson (2011), o aluno de arquitetura deve conhecer e utilizar a tecnologia à medida que ela se desenvolve. Desta forma, considerando a sala de aula um espaço essencial para a incorporação de produções arquitetônicas diferenciadas (Secchi, 2019), a inserção do sistema construtivo WikiHouse sugere grandes avanços e aprendizados aos acadêmicos. Diante do contexto apresentado, o objetivo da pesquisa é introduzir o sistema construtivo WikiHouse versão 3.0 em ateliê de arquitetura, buscando aproximar o aluno dos métodos construtivos, a partir de conceitos que aliem tecnologia e colaboração, tendo como produto final um mobiliário urbano.

\section{WIKIHOUSE VERSÃO 3.0}

Desde sua criação, a Wikihouse sofreu adaptações de diferentes pesquisadores no mundo inteiro. Estas versões foram disponibilizadas em plataformas open source, dentre as quais pode-se citar o site Wikihouse (https://www.wikihouse.cc/), $\quad$ e $\quad 0 \quad$ GitHub 
(https://github.com/search?q=wikihouse). O Laboratório de Modelos e Fabricação Digital (LAMO), pertencente ao Programa de Pós-Graduação em Urbanismo (PROURB) da Faculdade de Arquitetura e Urbanismo da Universidade Federal do Rio de Janeiro (UFRJ), se destaca como precursor na adaptação deste sistema construtivo a realidades brasileiras. Com pesquisas desde 2013, materializou no ano de 2015 a Casa Revista, primeira versão da Wikihouse na América Latina (Mendonça et al., 2018).

Estes estudos resultaram na versão WikiHouse 3.0 criada por David Mendonça, no seu Trabalho de Conclusão de Curso em 2016, também na UFRJ, sob orientação de Andrés Passaro e Gonçalo Castro Henriques. Neste projeto foram trabalhadas duas limitações apontadas: a plataforma existente, na qual só era possível realizar as modificações e adaptações manualmente, por meio de um plug-in do software Sketchup; e a geometria, que só permitia modelos ortogonais, ou seja, formas curvas não eram possíveis (Mendonça et al., 2018). Assim, o orientando e seus orientadores desenvolveram o primeiro sistema construtivo Wikihouse disponibilizado em plataforma generativa e paramétrica, que permite o uso de geometrias curvas e viabiliza infinitas experimentações, partindo de alterações nos parâmetros do modelo. O método desenvolvido funciona baseado no desenho de uma curva de eixo inicial, de geometria única, no software Rhinoceros, conectada ao sistema parametrizado no plugin Grasshopper. Este, por sua vez, projeta a estrutura em $3 \mathrm{D}$, gerando automaticamente os módulos, encaixes, conectores e peças, bem como planificações para posterior fabricação digital em maquinário CNC (Comando Numérico Computadorizado).

\section{METODOLOGIA}

A metodologia pode ser classificada como qualitativa, possuindo natureza aplicada, objetivo explicativo e procedimento de pesquisa-ação. A abordagem qualitativa é definida pelo aprofundamento da investigação, não sendo vinculada a dados numéricos, mas a aspectos de compreensão e explicação dos fenômenos estudados (Silveira \& Córdova, 2009). A natureza aplicada da pesquisa é assumida pela geração de conhecimentos por meio de aplicações práticas, neste caso, experimentação pedagógica (Silveira \& Córdova, 2009). Quanto ao objetivo, este pode ser definido como explicativo, pois o estudo se baseia nos resultados que explicam o problema levantado (Gil, 2017).

O procedimento, por sua vez, se caracteriza como uma pesquisa-ação. De acordo com Thiollent (1986), esse tipo de pesquisa possui como principais características o conhecimento empírico e a concepção por meio de uma ação, na qual os resultados são alcançados pela colaboração entre autores e participantes, ou seja, é uma investigação com base na experiência e observação. Desta forma, a pesquisa-ação admite a participação premeditada dos pesquisadores na experimentação, que possuem papel fundamental para a conclusão do estudo, baseado em seus próprios conhecimentos (Fonseca, 2002). Tripp (2005) reforça que a pesquisa-ação é, entre outros, um tipo de investigação-ação, determinada por processos que envolvem ciclos de práticas, com intuito de aprimorar ações de maneira continuada. Utiliza técnicas de pesquisa experimentais, pois depende da ação para compreender os resultados, ou seja, é uma reflexão da prática, sendo necessária a verificação do processo para chegar a conclusões de melhorias (Tripp, 2005).
O ciclo da pesquisa-ação é composto por três fases, que podem ser realizadas tanto no campo da prática quanto da investigação, sendo elas: Planejamento, Implementação e Avaliação (Tripp, 2005). Estas etapas são definidas nesta pesquisa como "Estruturação da experimentação pedagógica", "Aplicação em ateliê de arquitetura" e "Resultados, discussões e contribuições", respectivamente (Figura 1).

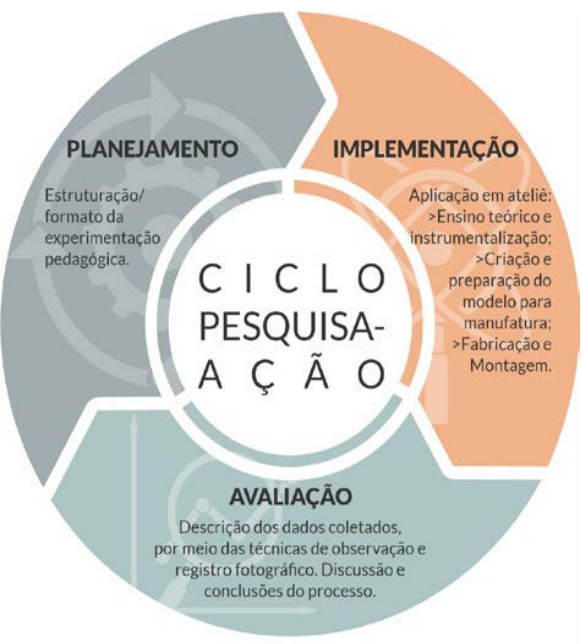

Figura 1: Ciclo da pesquisa-ação. Fonte: Freepik, adaptado pelos autores (2020)

Por se tratar de uma pesquisa empírica, as técnicas de coleta de dados utilizadas foram a observação por meio de conversas informais com os alunos ao longo da experimentação, complementada com registro fotográfico.

\section{ESTRUTURAÇÃO DA EXPERIMENTAÇÃO PEDAGÓGICA}

A experimentação pedagógica ocorreu na disciplina de "Fabricação Digital e Prototipagem Rápida", do terceiro período, da matriz curricular do curso de Arquitetura e Urbanismo da Universidade Comunitária da Região de Chapecó - UNOCHAPECÓ. Ocorreu ao longo de cinco semanas com duas turmas do primeiro semestre do ano de 2019, totalizando 20 alunos participantes, sendo 09 da Turma A e 11 da Turma B, em encontros semanais. A disciplina possui como objetivo introduzir aos estudantes conceitos de modelo, maquete e protótipo; Fabricação Digital (FD); Prototipagem Rápida (PR); Modelagem Paramétrica (MP); tipos de materiais e tecnologias de digitalização 3D; e geometria descritiva aplicada. Desta forma, viu-se como pertinente inserir o sistema construtivo Wikihouse a ela, uma vez que já prevê o ensino de conhecimentos e ferramentas necessários para sua efetivação. Outro diferencial favorável é o acesso ao laboratório de prototipagem e fabricação digitais PRONTO 3D Chapecó, localizado na universidade, com uso previsto no cronograma da disciplina, que possibilitou a realização da experiência aqui relatada.

A atividade ocorreu em dois espaços da universidade: laboratório de informática, no qual o projeto e planificação foram desenvolvidos; e laboratório PRONTO 3D Chapecó, no qual a proposta foi materializada, ambos por meio de 
ferramentas específicas. No primeiro plano foram utilizados computadores, com os seguintes softwares: Rhinoceros, plug-in Grasshopper, plug-in Lunchbox, plugin FabTools e plug-in Pufferfish. Já no segundo, utilizou-se maquinário de corte Router $\mathrm{CNC}$, associado aos materiais: MDF de espessura $18 \mathrm{~mm}$, compensado flexível de espessura $6 \mathrm{~mm}$, parafusos, lixadeira elétrica, parafusadeira, tinta verniz e utensílios auxiliares para lixamento e pintura.

Com relação às limitações da aplicação da experimentação, tem-se como fator crucial o tempo necessário para o completo desenvolvimento da proposta. Tal dificuldade é apontada devido à inserção da atividade no final do cronograma já previsto da disciplina. Outro fator impactante é o reduzido conhecimento técnico dos alunos a respeito de processo de projeto em geral, já que estão apenas no terceiro período da graduação. Devido a essas limitações, definiu-se como escopo da atividade de experimentação, a criação e materialização de um mobiliário urbano, a ser instalado no campus da universidade. Optou-se por inserir a atividade na etapa final da disciplina, para que os acadêmicos já possuíssem conhecimentos gerais sobre fabricação e prototipagem digitais. A escala e complexidade do objeto tornam possível sua realização no prazo disponível, além de ser de fácil interpretação por parte dos alunos.

\section{APLICAÇÃO EM ATELIÊ DE ARQUITETURA}

A aplicação da experimentação pedagógica ocorreu ao longo de cinco aulas, sendo uma por semana, com duração de 3 horas e 30 minutos. Os conteúdos foram ministrados simultaneamente para as duas turmas da disciplina, conforme cronograma e etapas a seguir:

a) Semana 01: ensino teórico e instrumentação prática dos softwares e do sistema construtivo WikiHouse versão 3.0, bem como lançamento da atividade de concepção do mobiliário urbano.

b) Semanas 02 e 03: criação e preparação do modelo para manufatura.

c) Semanas 04 e 05: fabricação em maquinário Router CNC, acabamento das peças e montagem do mobiliário urbano.

\section{RESULTADOS E DISCUSSÕES}

A coleta de dados para efetivação dos resultados ocorreu ao longo do processo de experimentação. Resultado da observação das reações dos alunos ao lançamento e desenvolvimento de cada etapa, compreensão do objetivo da proposta, qualidade do material entregue e análise do resultado final. Estes fatores são reforçados com registro fotográfico de cada estágio avançado. Como os resultados de ambas as turmas foram similares, descreve-se a realização em conjunto.

$\mathrm{Na}$ Semana 01, no laboratório de informática da universidade, deu-se início à experimentação pedagógica com a abordagem dos temas Arquitetura Open Source e WikiHouse, seguidos da caracterização específica de sua versão 3.0. A exemplificação de modelos já existentes pelo mundo, a partir de vídeos e fotografias, despertou interesse e curiosidade nos alunos, sendo levantados questionamentos a respeito das possibilidades oferecidas por essa metodologia.
Por conta da ementa da disciplina, os acadêmicos já haviam tido contato introdutório com os softwares Rhinoceros e o plug-in Grasshopper, anteriormente ao lançamento da proposta, com exemplos práticos e básicos. Desta forma, iniciou-se a instrumentação prática do sistema construtivo (Figura 2), explanando a respeito do funcionamento geral dos grupos de elementos do algoritmo, quais componentes podem e/ou devem ser alterados, como também explicações específicas da habilitação de baterias que influenciam na visualização do modelo.

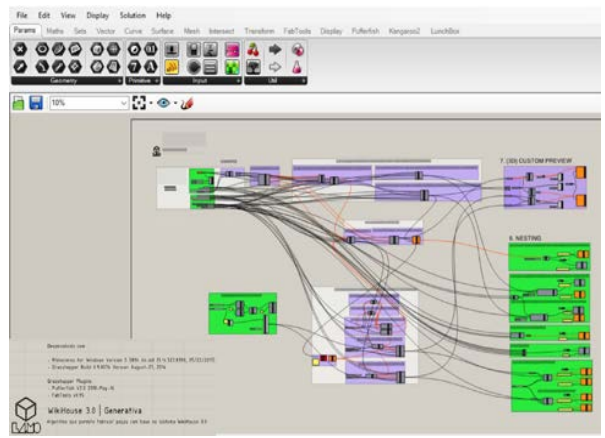

Figura 2: Ferramenta generativa e paramétrica da Wikihouse versão 3.0. Fonte: Mendonça et al. (2018), adaptado pelos autores.

Foram feitas orientações a respeito do desenvolvimento do desenho da curva de eixo inicial no software Rhinoceros, a qual é conectada à ferramenta generativa e paramétrica da Wikihouse no plug-in Grasshopper por meio de uma bateria específica (Figura 3 ).

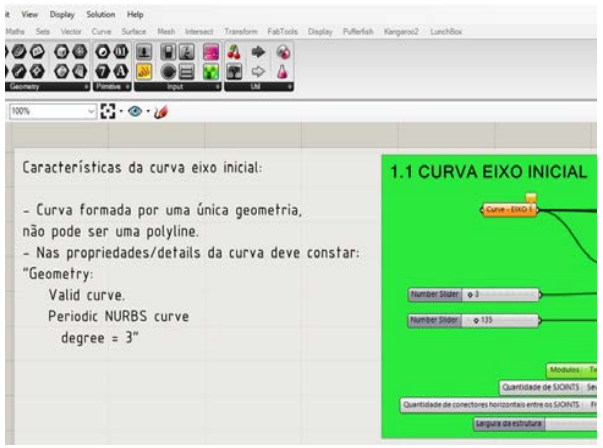

Figura 3: Instruções sobre a curva de eixo inicial e bateria que faz a ligação desta geometria com a Ferramenta generativa e paramétrica da Wikihouse versão 3.0. Fonte: Mendonça et al. (2018), adaptado pelos autores.

Como forma de auxiliar o processo criativo do mobiliário e adequar os resultados às possibilidades de corte no maquinário Router $\mathrm{CNC}$, os alunos foram orientados a propor suas criações internamente a uma geometria de um quadrado de lado 3 metros (Figura 4). 


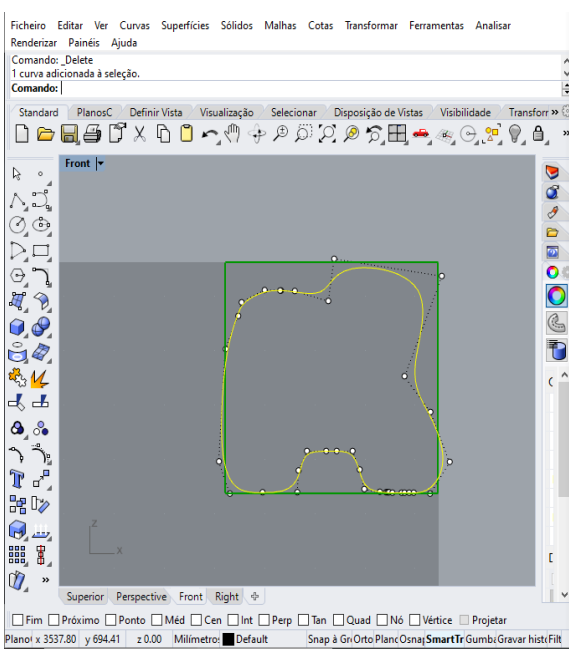

Figura 4: Em verde o quadrado de lado $3 \mathrm{~m}$, em amarelo a curva de eixo inicial e em branco os nós da curva editáveis. Fonte: os autores.

Após os alunos praticarem a familiarização com a metodologia e com os softwares, experimentando diferentes possibilidades de geometrias no sistema parametrizado, foi lançada a atividade prática de experimentação. Esta etapa foi desenvolvida de forma individual, sendo responsáveis pela criação de um mobiliário urbano passível de ser instalado no campus da universidade. Neste momento os acadêmicos demonstraram interesse no trabalho a ser realizado, principalmente pelo diferencial de fabricá-lo em tamanho real, algo incomum nas demais disciplinas ao longo da graduação, devido às escalas de trabalho. Outro fator relevante foi a disponibilização do resultado final no campus da instituição, podendo ser utilizado pelos próprios e por outros.

Foi orientado que desenvolvessem extraclasse esboços à mão da geometria curva desejada, para adiantamento das atividades no decorrer do cronograma, já que o trabalho com os softwares poderia ser feito apenas no horário de aula, no laboratório onde são oferecidas estas tecnologias.

Nas Semanas 02 e 03 os alunos tiveram liberdade de criação e experimentação de diferentes possibilidades de forma, assessorados pela docente. No momento de desenho da geometria, os acadêmicos encontraram dificuldades de conclusão, pois o traçado deve ser feito de uma só vez, gerando um elemento único. Orientou-se que o desenvolvessem no plano de visualização da vista frontal do modelo, no software Rhinoceros, para evitar erros na geometria e facilitar o processo dificultoso. Pela falta de prática com os sistemas, os estudantes interrompiam o desenho da curva e continuavam com outro segmento, por conta disso, o programa não aceitava e gerava erros. Essa etapa exigiu um assessoramento maior aos alunos por parte da professora, e se mostrou um problema frequente durante a atividade.

Sendo a base do mobiliário o plano de equilíbrio do objeto, é necessário editar os nós da geometria criada, para aumentar sua estabilidade. Este processo se deu de maneira extensa e gerou dúvidas, também sendo necessária orientação da docente, por diversas vezes de forma individual. O desenho da curva de eixo inicial se mostrou como o principal problema encontrado pelos alunos, pois ângulos muito fechados dificultam a colocação de encaixes denominados S-Joints (Figura 5). Este fator é resolvido a partir da suavização da geometria, o que muitas vezes não atendeu às expectativas iniciais dos alunos em relação às suas criações. É importante ressaltar que, além das mudanças na geometria, era necessário realizar testes com as quantidades de S-joints e de conectores horizontais entre os S-joints (Figura 6), pois dependendo da quantidade e posição interferem na validação ou não do modelo.

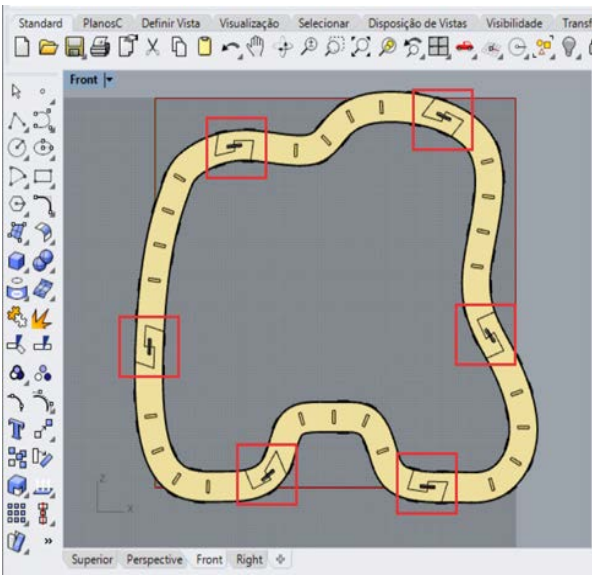

Figura 5: Encaixes S-Joints destacados em vermelho. Fonte: os autores.

Standard Planosc Definir Vista Visualizaçâo Selecionar Disposiçâode Vistas Vsibilidade Transfo

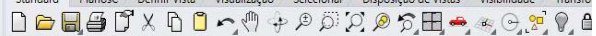

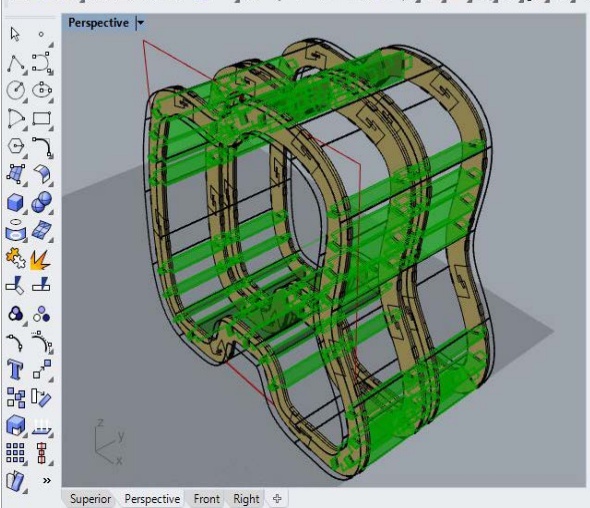

Figura 6: Conectores horizontais destacados em verde. Fonte: os autores.

Ao fim da terceira semana, foi orientada a finalização das propostas com a preparação dos arquivos para fabricação digital. O processo de planificação das peças é gerado automaticamente pelo sistema, sendo necessária intervenção do aluno na otimização das chapas de corte, diretamente no software Rhinoceros. Até este momento todos foram responsáveis individualmente por suas criações. 
Com a conclusão desta etapa, a docente da disciplina desenvolveu uma avaliação dos mobiliários criados por cada aluno, e escolheu dois, um por turma, para materialização (Figuras 7 e 8). Os critérios adotados foram originalidade da proposta, aproveitamento das chapas de corte e conceitos formais distintos entre ambos. Optou-se por esta seleção devido aos custos à universidade e tempo disponível para corte e montagem, visando ainda o trabalho cooperativo entre os alunos no processo de fabricação.

Ficheiro Editar Ver Cunvas Superficies Solidos Malhas Cotos transtormar Ferramentas Anolisat Renderizat Paineis Ajuds

Comandoc pan
Clique earrate

Comando:

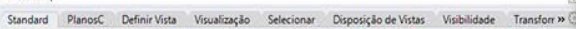

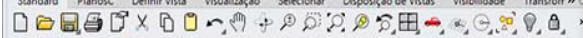
Perspective $F$

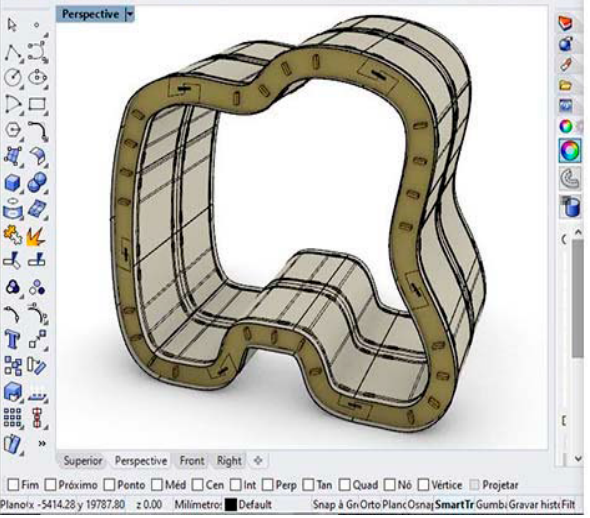

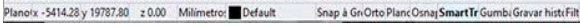
Figura 7: Mobiliário Turma A. Fonte: os autores.

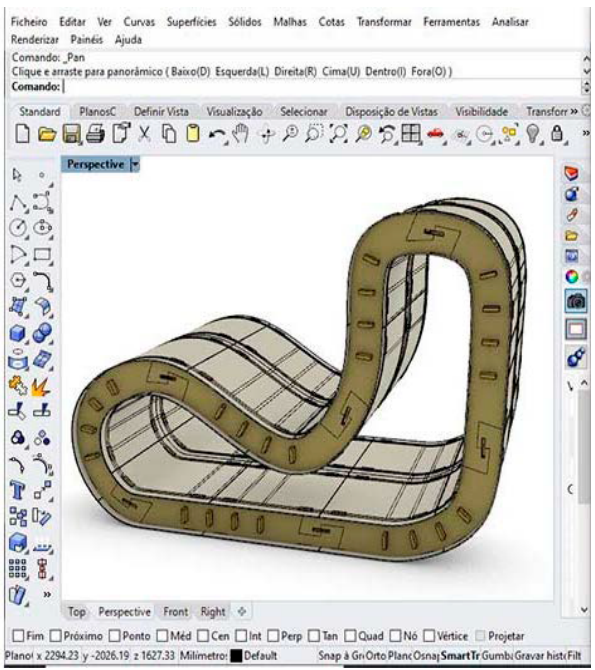

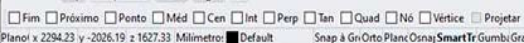

Figura 8: Mobiliário Turma B. Fonte: os autores.

O sistema generativo Wikihouse 3.0 possibilita a produção de até dez módulos de uma única vez, porém, por conta do tempo e material, foi fabricado somente um módulo de cada mobiliário, contemplando o objetivo da atividade. Para os painéis interiores e exteriores utilizou-se compensado flexível de espessura $6 \mathrm{~mm}$, devido às suas propriedades de envergadura, e no restante MDF
(Medium-Density Fiberboard ou Placa de fibra de média densidade) de espessura $18 \mathrm{~mm}$. Ressalta-se que o MDF não é um material recomendado para exposição às intempéries, contudo foi o disponibilizado pela universidade, pela grande quantidade em estoque. Para o compensado foram utilizadas chapas cortadas na dimensão de 1,60x0,83 metros, que se mostrou efetiva no aproveitamento de material, associado à possibilidade de encaixe para corte na Router CNC; e para o MDF, chapas de 1,00x2,00 metros, que é o tamanho máximo aceito pelo equipamento. As planificações foram exportadas do software Rhinoceros na extensão "DXF", para leitura no software do maquinário. Ao todo, foram necessárias 24 chapas de compensado e 28 chapas de MDF (Figuras 9 e 10).

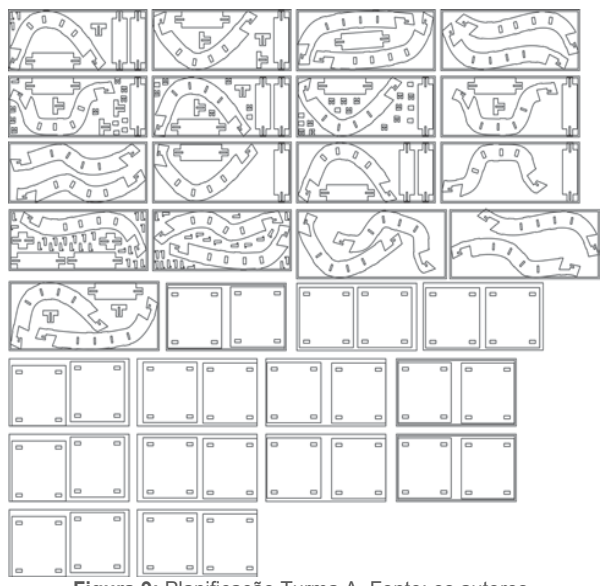

Figura 9: Planificação Turma A. Fonte: os autores.

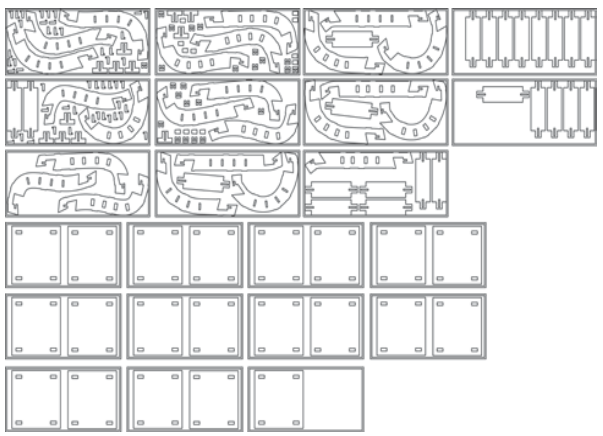

Figura 10: Planificação Turma B. Fonte: os autores.

Devido ao tempo exigido para finalização do corte das peças planificadas, optou-se pelo adiantamento desta etapa entre a terceira e quarta semana, em horários extraclasse, pela técnica responsável do laboratório de prototipagem e fabricação digitais. Parte das peças foram mantidas para corte durante a aula, na Semana 04, assim os alunos tiveram a oportunidade de acompanhar este processo. Conforme as chapas eram cortadas pela Router $\mathrm{CNC}$, os acadêmicos desenvolveram o acabamento nos elementos, com lixas, limas e lixadeira elétrica, bem como pintura em verniz marítimo, para que o mobiliário atingisse maior resistência ao ser exposto às intempéries no campus da universidade (Figura 11). Os alunos demonstraram interesse e curiosidade ao assistirem o funcionamento da máquina de corte, tal qual pelo processo da manufatura do 
acabamento, algo que a maioria ainda não havia experimentado.

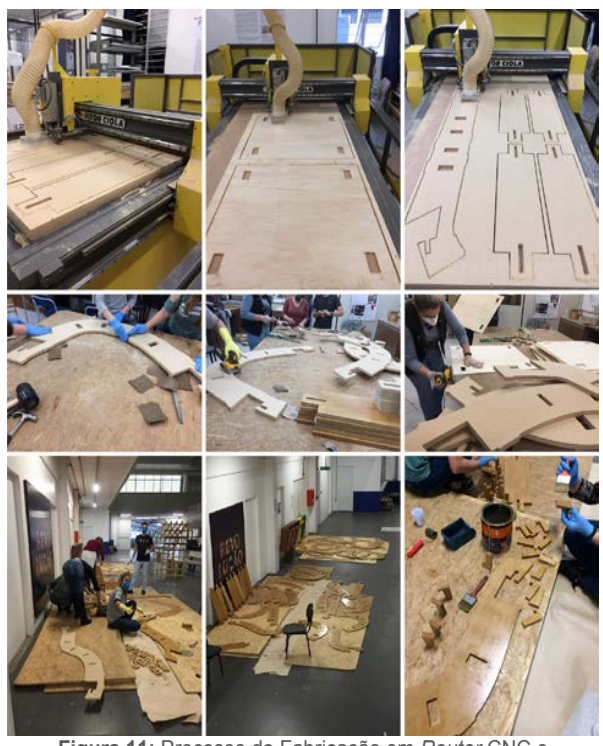

Figura 11: Processo de Fabricação em Router CNC e acabamento das peças. Fonte: os autores.

Todavia, esse processo não foi finalizado no horário de aula disponível na Semana 04, devido ao grande número de itens e demanda de tempo do trabalho manual. Foi solicitado aos alunos que se organizassem, conforme sua
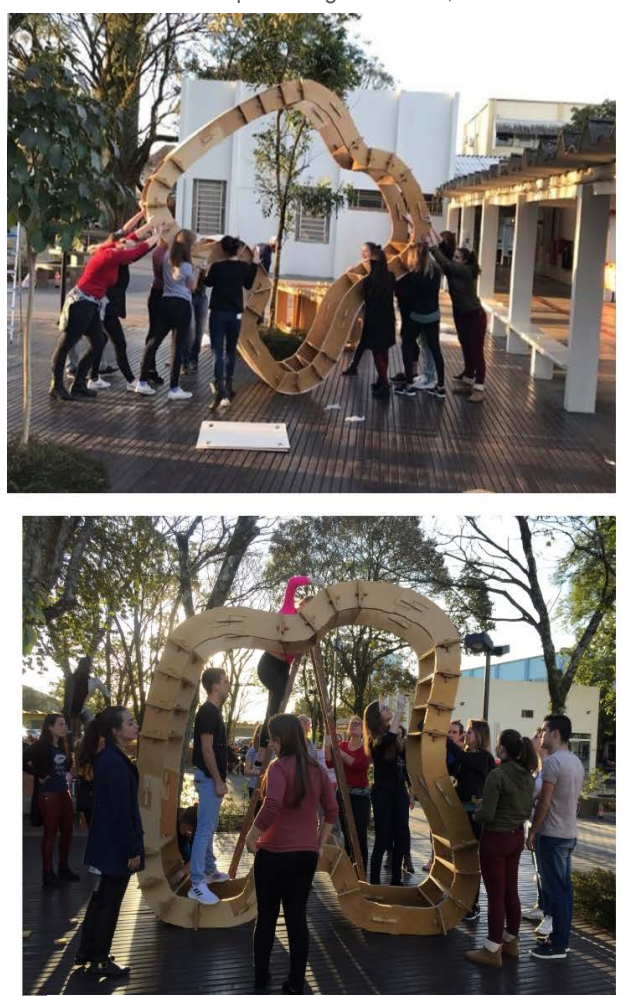

Figura 13: Montagem do mobiliário Turma A. Fonte: os autores. disponibilidade, em grupos e finalizassem a atividade no decorrer da semana, no laboratório, para que a montagem dos mobiliários pudesse ocorrer condizente ao cronograma. As turmas se mostraram engajadas no processo, não havendo oposição à solicitação de trabalho extra, mas sim interesse e voluntariedade.

A quinta e última semana da experimentação foi destinada à montagem dos objetos, em área externa no campus da universidade, no qual seriam mantidos após finalização, evitando transporte. Ambas as turmas foram reunidas em uma tarde para realização da atividade em conjunto, e consequentemente, cada mobiliário foi montado simultaneamente, com supervisão da docente da disciplina e da técnica do laboratório. Foram utilizados notebooks para consulta da sequência de encaixe de acordo com os projetos. Os alunos se mostraram empolgados com a materialização de uma criação própria, ansiosos para produção e conferência do resultado final.

O início da montagem se mostrou um processo demorado, pois os elementos eram duplicados e precisavam ser devidamente encaixados, para conexão com os demais e qualidade no acabamento. Soma-se à grande quantidade de peças e uniões, que mesmo com a consulta aos projetos, se tornou um desafio a interpretação geral do modelo. Após o entendimento do funcionamento dos encaixes por parte dos alunos, o processo fluiu com tranquilidade (Figura 12).
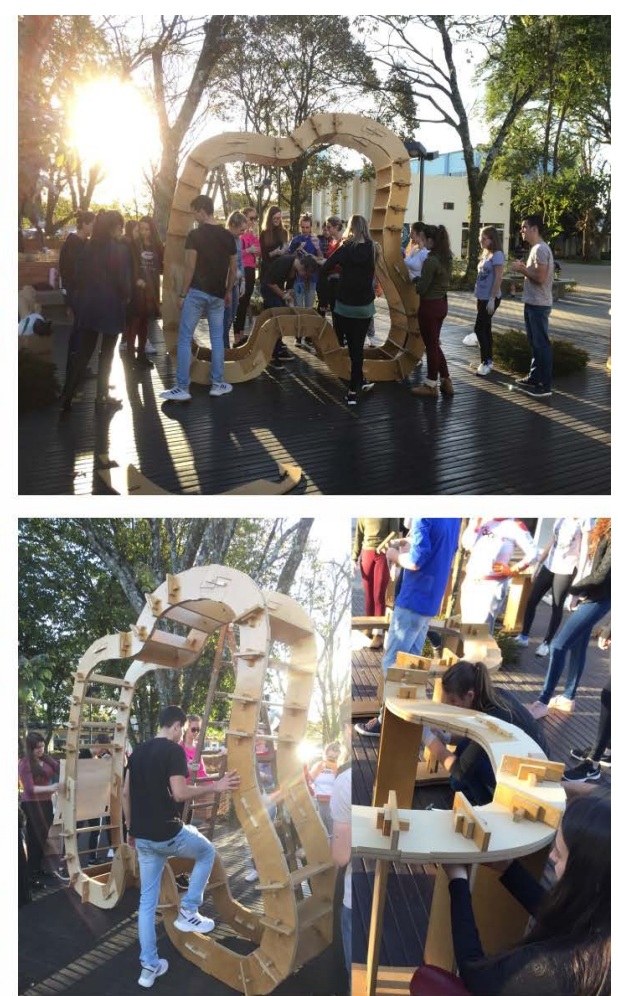


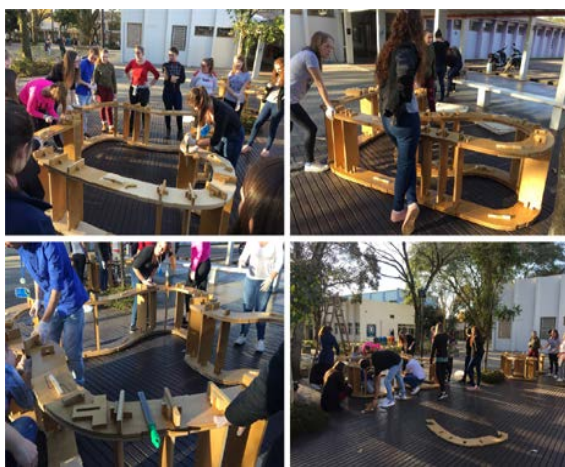

Figura 12: Montagem dos mobiliários. Fonte: os autores.

O maior desafio dos acadêmicos foi realizar a montagem do mobiliário da Turma A, que por conta da altura, precisou de uma colaboração extra dos estudantes (Figura 13). Mesmo com a flexibilidade do material dos painéis de fechamento externos e internos, as curvas dos modelos possuíam ângulos fechados, e exigiram grande esforço para encaixe das uniões. Devido à essa dificuldade, esses elementos precisaram ser parafusados, contudo, o restante da estrutura foi montado somente a partir dos encaixes previstos no sistema generativo.

Ao fim do processo, o resultado dos mobiliários esteve coerente com o objetivo da proposta, sem grandes problemas ao longo do percurso. Os alunos se mostraram realizados com o produto final, orgulhosos por terem feito parte do processo do início ao fim (Figura 14).
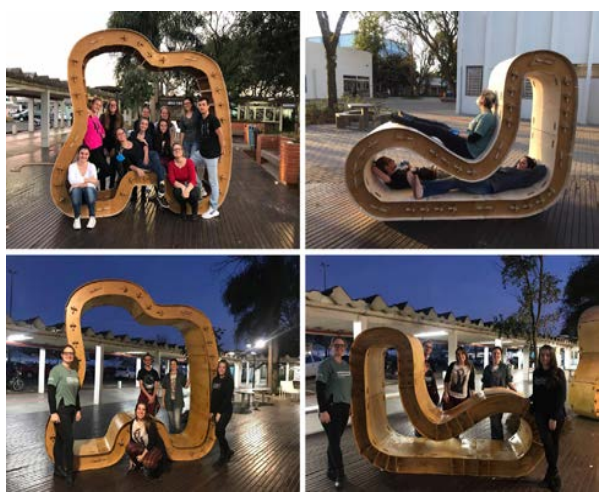

Figura 14: Mobiliários finalizados. Fonte: os autores

Os mobiliários permaneceram no pátio externo do campus da universidade durante cinco meses, até o momento em que foram retirados devido à degradação pela exposição às intempéries. Durante este período, estiveram em constante uso por parte de frequentadores da instituição de ensino, despertando interesse e curiosidade também nos demais.

\section{CONCLUSÕES}

Inicialmente, pode-se concluir que a atividade atingiu os objetivos acadêmicos esperados, com projetos entregues alcançando níveis de aprofundamento bastante similares entre si. Percebe-se que o entendimento da metodologia foi avançado no processo individual de modelagem dos mobiliários, mas efetivamente se consolidou na fabricação e montagem em conjunto.

O desafio inicial de inserir o processo em um componente curricular já existente, se mostrou dificultoso quanto ao tempo disponível, pois, em alguns momentos, foi solicitada participação extraclasse. Contudo, o anterior conhecimento dos softwares e conceitos gerais de parametrização e fabricação digital se mostraram fundamentais para o êxito da atividade.

Apesar de não ter sido possível realizar a fabricação dos mobiliários de todos os alunos, a proposta de trabalho em conjunto agregou à atividade. A necessidade de colaboração na montagem aproximou os alunos e os concentrou em prol de um objetivo conjunto. Notou-se a criação de uma relação de pertencimento aos mobiliários executados, advinda da sensação de orgulho da finalização e sucesso do projeto.

Quanto às recomendações sobre o desenvolvimento de um mobiliário urbano baseado no processo construtivo Wikihouse versão 3.0, ressalta-se que, devido ao porte, aconselha-se inserir um número maior de conectores horizontais. Em alguns casos, onde ocorreram grandes espaçamentos, com o passar do tempo, o material do compensado flexível não respondeu de forma efetiva ao peso constante de usuários, necessitando reparos ao longo de sua vida útil.

A aplicação do sistema construtivo WikiHouse em ateliê de arquitetura contribui para a percepção e compreensão de novas formas de produção arquitetônica por parte dos alunos. Aliar o emprego desta tecnologia desde o início da caminhada acadêmica, propicia um novo olhar para a produção e materialização dos projetos. Confirma assim, a importância que a fabricação e prototipagem digitais vêm desempenhando no campo da arquitetura e do urbanismo

Desde o primeiro momento os alunos foram instigados pelo tema, e mostraram-se interessados do início ao fim da atividade. Os estudantes adquiriram conhecimentos em softwares essenciais para a parametrização, participando ativamente da criação, fabricação, acabamento e montagem de um novo sistema construtivo. Destaca-se que esta não necessitou de mão de obra qualificada, sendo realizada pelos próprios estudantes, reforçando os conceitos de Open Source Architecture e Wikihouse.

Pretende-se realizar novamente a experimentação com outras turmas da mesma disciplina, implementando pequenos ajustes, como uso de materiais mais resistentes às intempéries. Esta experimentação continuada fortalece a definição da pesquisa-ação, por meio de ciclos de aprimoramentos. Entende-se como essencial a introdução desses métodos inovadores no ensino de Arquitetura e Urbanismo, além de aliar materiais e técnicas sustentáveis, em prol do bem estar social e humanitário.

\section{AGRADECIMENTOS}

Agradecemos o curso de Arquitetura e Urbanismo da UNOCHAPECÓ, por acreditar nas tecnologias e oportunizar tais experiências, como também aos alunos que participaram da atividade e toparam o desafio com entusiasmo e dedicação. 
Um agradecimento especial aos ensinamentos repassados por David Mendonça e Gonçalo Castro Henriques, no 'Workshop Wikihouse', no SiDradi 2018, em que as pesquisadores deste estudo tiveram a oportunidade de participar.

\section{REFERÊNCIAS}

Fonseca, J. J. S. (2002). Metodologia da pesquisa cientifica. Fortaleza: UEC.

Gil, A. C. (2017). Como elaborar projetos de pesquisa. (Vol. 6). Rio de Janeiro: Atlas.

Lawson, B. (2011). Como arquitetos e designers pensam. São Paulo: Oficina de Textos.

Mendonça, D., Passaro, A., \& Henriques, G. C. (2018).

WikiHouse: A Generative and parametric tool to customize curved geometries. Blucher, 714-718. doi: 10.5151.

Parvin, A. (2013). Architecture (and the other 99\%): open-source architecture and the design commons., 90-95.
Passaro, A., \& Rohde, C. (2015). Casa Revista: arquitetura de fonte aberta. Blucher, 70-76. doi: 10.5151.

Pupo, R. T. (2009). Inserção da prototipagem e fabricação digitais no processo de projeto: um novo desafio para o ensino de arquitetura. (doutorado). Universidade Estadual de Campinas, Campinas, SP.

Ratti, C. (2011). Open Source Architecture (OSArc). Domus, 948, 3-4.

Secchi, C. C. (2019). Arquitetura Open Source: Capacitação, Criação e Materialização com Suporte da Fabricação Digital. (Dissertação Mestrado). Universidade Federal de Santa Catarina, Florianópolis.

Silveira, D. T., \& Córdova, F. P. (2009). UNIDADE 2 - A PESQUISA CIENTÍFICA. In E. d. UFRGS (Ed.), Métodos de pesquisa (pp. 31-42).

Thiollent, M. (1988). Metodologia da pesquisa-ação. São Paulo: Cortez \& Autores Associado.

Tripp, D. (2005). Pesquisa-ação: uma introdução metodológica. Educação e Pesquisa, 31, 443-466. 